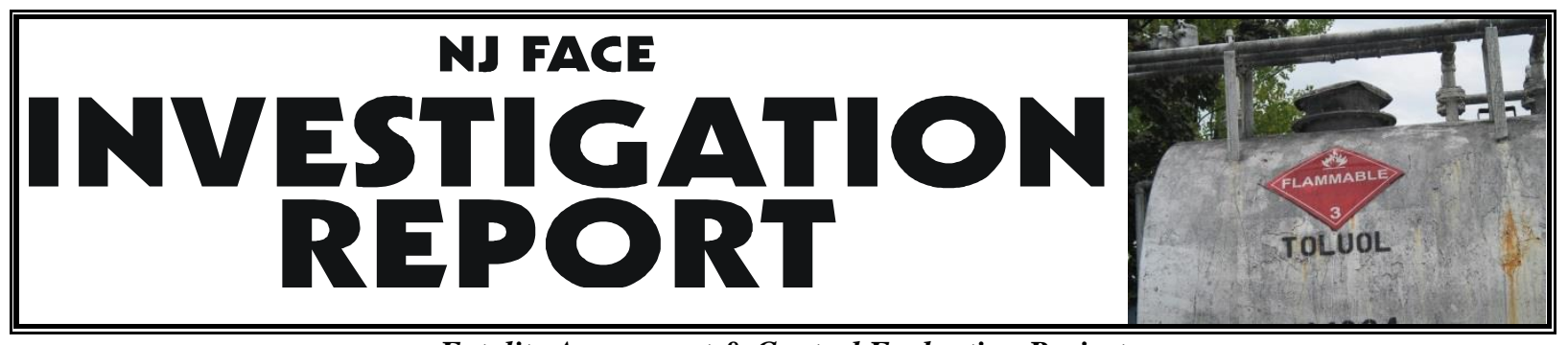

Fatality Assessment \& Control Evaluation Project

FACE 13-NJ-059

May 21, 2015

\title{
Batch Maker Dies after Toxic Exposure to Toluene Vapor
}

A 56-year-old male batch maker died after a toxic exposure to toluol (toluene) vapor at a manufacturing plant. The incident occurred on the top of a 6,000-gallon, above-ground storage tank which was located outside of the plant. On the day of the incident, the victim was using a wooden measuring stick to determine the remaining volume of toluene in the tank. After he opened the port on the top of the tank, he lowered the measuring stick into the tank. He reached down into the port to obtain a measurement (the stick was shorter than the depth of the tank) and was overcome with vapor. Coworkers found the victim shortly afterwards laying on the top of the tank and 9-1-1 was called. Emergency responders arrived at the site and transported the victim to the hospital, where he died shortly afterwards. The cause of death was determined to be toluene intoxication.

Contributing Factors:

- Measuring stick was shorter than depth of tank

- High daytime temperature (approximately $95^{\circ} \mathrm{F}$ )

- Entry of permit required confined space

NJ FACE investigators recommend that these safety guidelines be followed to prevent similar incidents:

- A method to determine volume of product remaining in tank should be developed that does not put the worker at risk of exposure to volatile chemicals or confined space entry.

- Extra care should be taken when working with any volatile chemicals under high-temperature conditions.

- A safety and health plan based on a job hazard analysis should be developed by the employer and followed where workers are assigned tasks. 


\section{INTRODUCTION}

In summer 2013, NJ FACE staff was notified of the death of a 56-year-old male batch maker who died after a toxic exposure to toluene vapor. The incident occurred at a manufacturing plant in northern NJ.

An NJ FACE investigator contacted the OSHA Area Office and conducted a concurrent investigation. Additional information was obtained from the medical examiner's report, death certificate, police report, and the news.

\section{INVESTIGATION}

The incident occurred on an extremely hot summer day (approximately $95^{\circ} \mathrm{F}$ at the time of the incident, wind speed up to about $12 \mathrm{mph}$ ), with no significant precipitation recorded. The incident site was located in the backyard of a manufacturing plant in northern NJ. The company manufactures varnishes, lacquers, enamels and other coatings. A total of 12 nonunion workers are employed on site. The incident occurred on the top of a 37-year-old, 6,000-gallon above-ground storage tank, separated into three 2,000 gallon sections used for storage of toluene, ethyl acetate, and butyl acetate (Figure 1). The cylindrical tank was 16 feet (192 inches) in length by eight feet (96 inches) in depth. The tank access was an 18inch diameter access port, 12 inches in height (Figure 2). The total distance from the tip of the port to the bottom of the tank was nine feet (108 inches).

Two batch makers were trained by the plant manager to measure the volume of liquid in each section by using an 84-inch-tall wooden measuring stick (Figure 3). Measurements were taken either daily or every other day in order to determine if additional solvent needed to be ordered. The tank-level gauges were not functioning, and volume measurements had been conducted manually for approximately the past 30 years.

On the day of the incident, at approximately 3:00 pm, the victim was assigned to measure the volume of toluene remaining in the tank. The plant manager and the other batch maker clocked out at about 3:45 $\mathrm{pm}$ and headed to the plant manager's car (the other worker and the victim usually ride home with the plant manager). They started to drive off and realized that the victim was not with them. When they returned to the plant, they found the victim laying down with his head and part of his upper body in the tank. The coworker rushed to the top of the tank, pulled the victim out (by the belt), laid him across the feed pipes on the top of tank, and yelled to the plant manager to call 9-1-1. The coworker noticed a dark 
brown/green frothy secretion near the victim's nose and mouth.

When the EMTs arrived on scene (the response occurred in less than 20 minutes as the station house was only 2.7 miles from the incident site), one of the responders used a portable ladder, climbed on top of the tank to assess the victim, and felt a faint pulse. Using a Stokes basket (a metal or plastic stretcher sometimes used in rescue operations), they lowered the victim off the tank, rushed him to the ambulance and closed the doors. The ambulance did not depart immediately; they had to first attempt to stabilize the victim, which included respirations (through use of a bag-valve-mask unit), chest compressions, and then intubation. The ambulance then left and drove approximately 10 minutes to the nearest hospital. Upon arrival at the emergency room, several of the EMTs in the ambulance had to be decontaminated due to possible toluene exposure. One EMT was admitted. The victim was pronounced dead in the decontamination area of the hospital. The cause of death was determined by the Medical Examiner to be toluene intoxication.

All of the EMTs who transported the victim to the hospital fully recovered. NJ FACE staff notified NJ Public Employees Occupational Safety and Health (PEOSH) Program of the incident, as the EMTs worked for the local municipality. 
FIGURE 1: Incident site, above-ground storage tank with three 2,000-gallon sections (a. side view; b. front view).

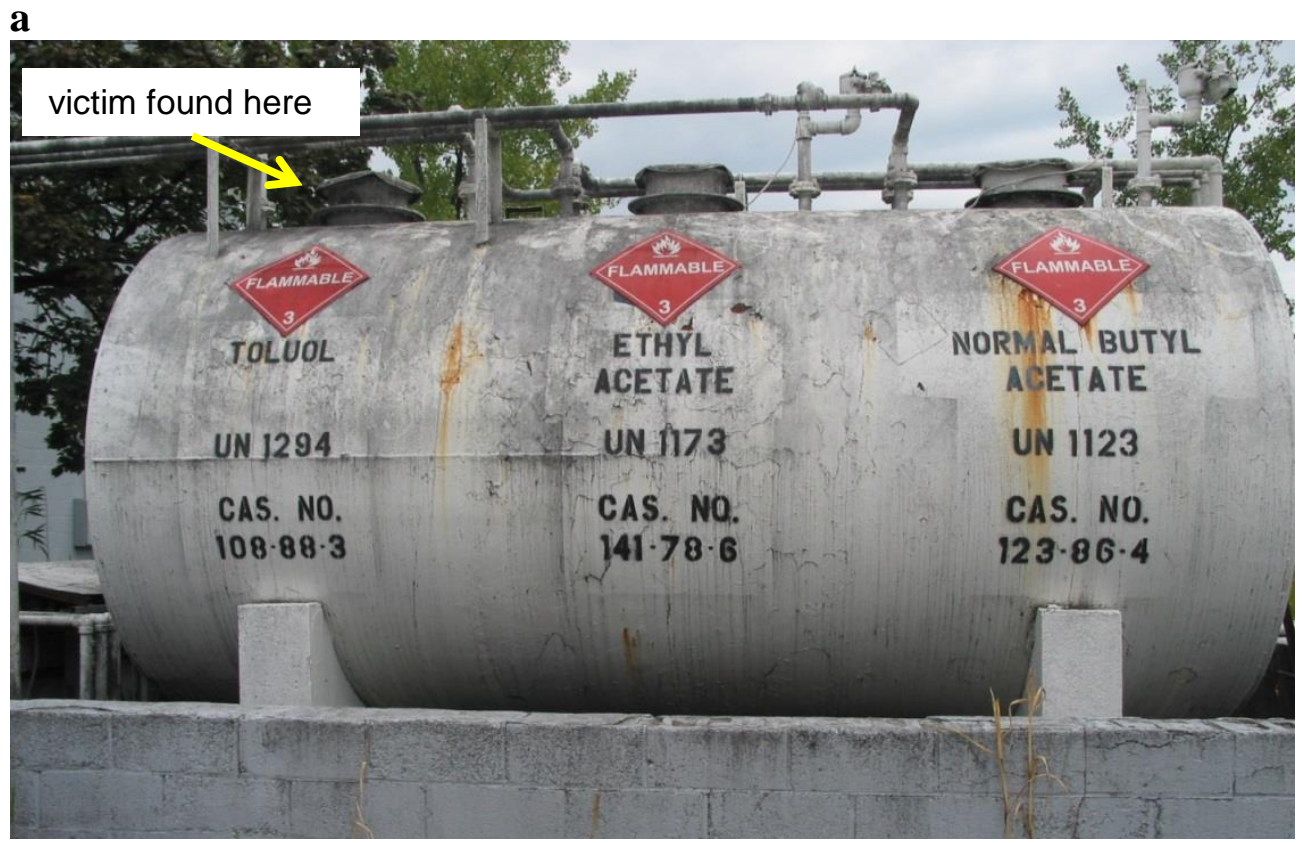

b

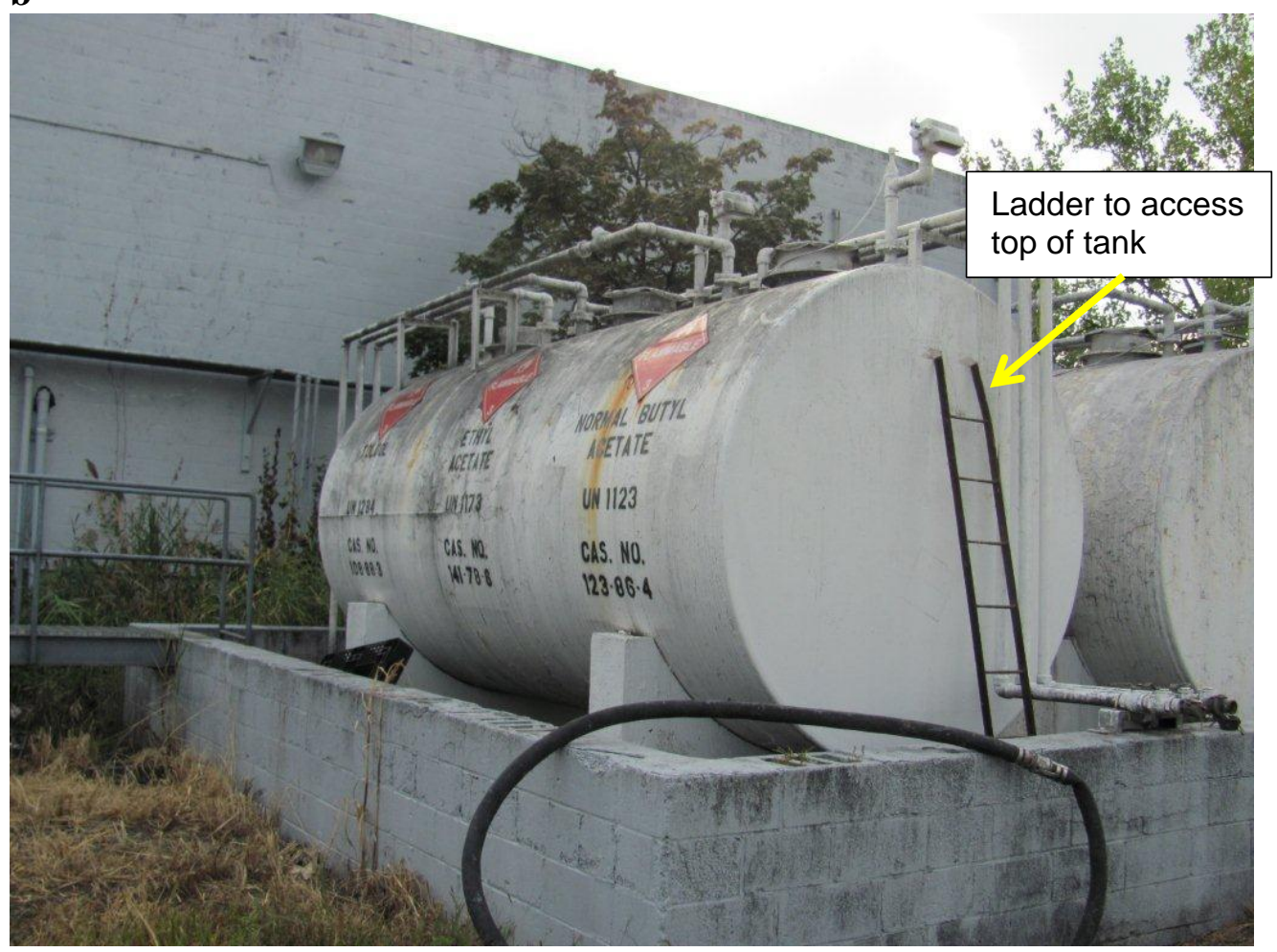


FIGURE 2.View of access port on top of tank.

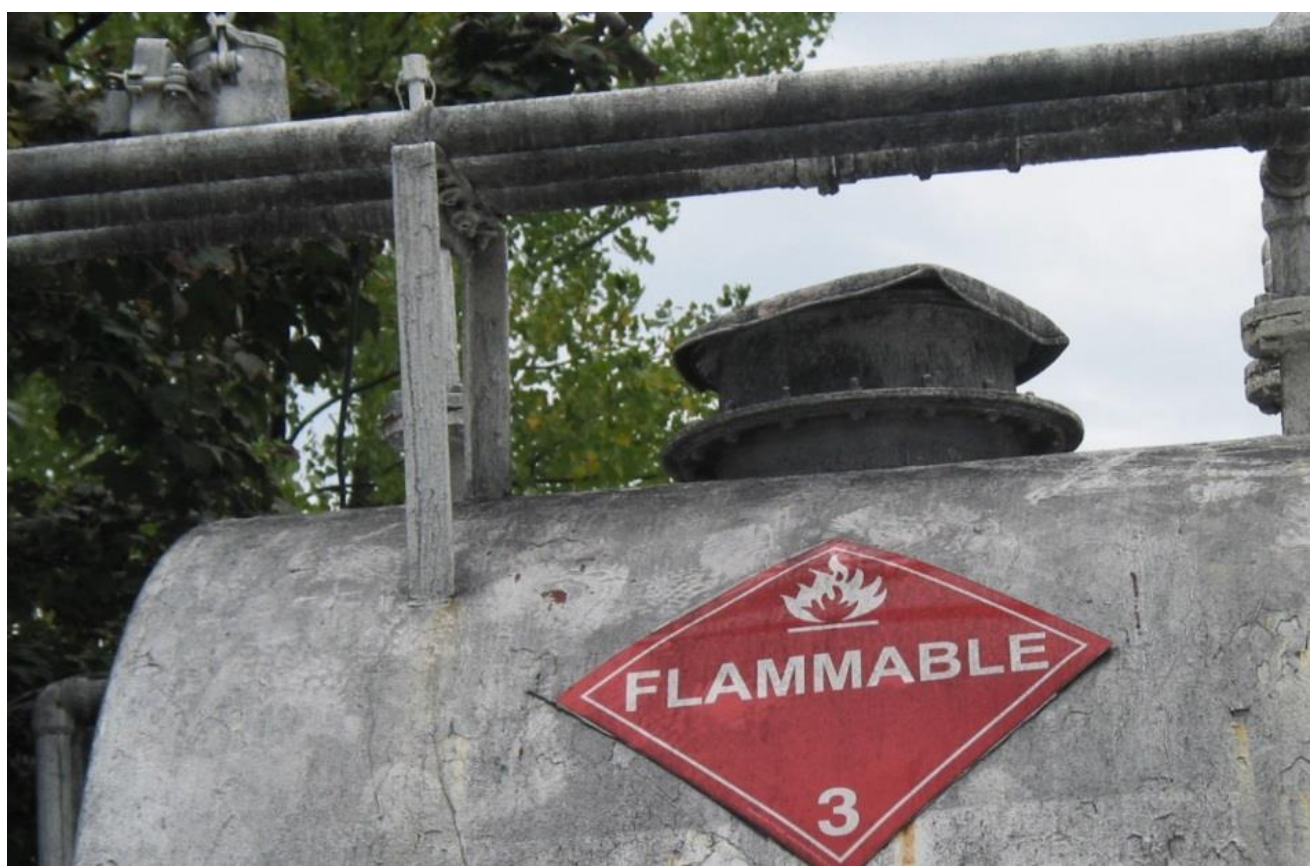

Figure 3. Eighty-four-inch-long wooden measuring stick used to manually gauge the volume of the remaining liquid in the tank.

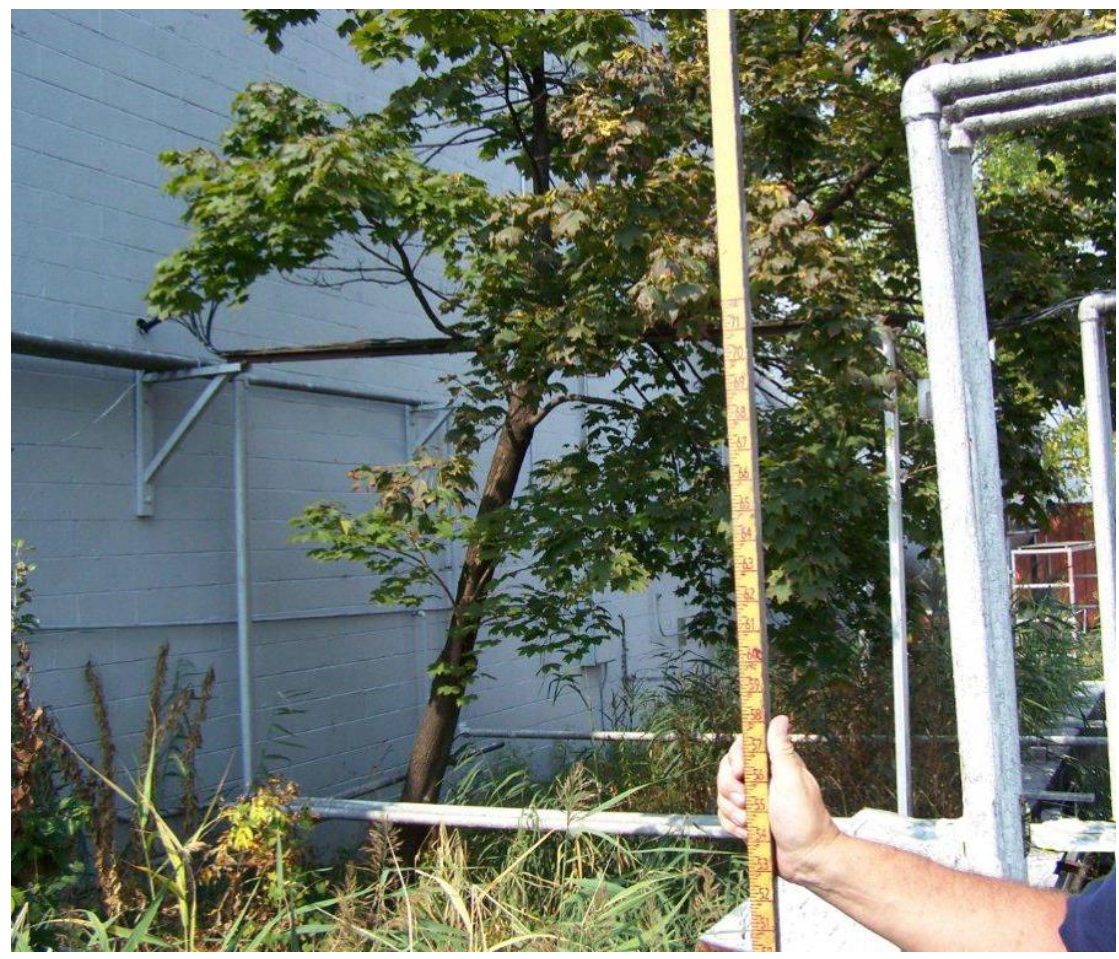




\section{RECOMMENDATIONS/DISCUSSIONS}

\section{Recommendation \#1: A method to determine volume of product remaining in tank should be developed that does not put the worker at risk of confined space entry or exposure to volatile chemicals.}

Discussion: According to 1910 146(b), entry into a confined space is considered to have occurred as soon as any part of the entrant's body breaks the plane of an opening into the space. ${ }^{1}$ As such, the job task of opening the hatch and inserting the stick into the tank is considered a confined space entry. The victim and the coworker would open the access port and lower the stick down to the bottom of the tank. Since the stick was eighty-four inches long, and the distance from the top of the hatch to the bottom of the tank was nine feet, the workers had to reach two feet into the tank into order to obtain an accurate volume measurement.

Entry into a permit required confined space triggers the need for a confined space entry program, which must include the following (at a minimum): posting signs, air quality/oxygen level testing and monitoring, availability of personal protective equipment (PPE), confined space and PPE training, emergency rescue procedures, and a written program. None of these were present at the incident site.

NJ FACE recommends developing a method of determining the volume of the liquid in the tank without entry. This can be accomplished in many ways, including retrofitting the tank with a small, sealed window for external view, fixing or replacing the volume gauges, or the creation of a permanent system that would indicate the remaining volume without the need for manual gauging. If an alternative method cannot be developed, the employer must comply with OSHA's confined space entry standard (CFR 29, 1910.146).

\section{Recommendation \#2: Extra care should be taken when working with any volatile chemicals under high-temperature conditions.}

Discussion: NJ FACE recommends that employers and employees be extra vigilant when working with or around volatile organic chemicals, such as toluene, under high temperatures. In this case, the tank was outside the plant and the outdoor temperature at the time of the incident was $95^{\circ} \mathrm{F}$. Due to the extreme temperature, a greater concentration of toluene vapor collected in the headspace of the tank, resulting in the high concentration to which the worker was exposed. In addition to the aforementioned recommendation of the elimination of manual gauging, NJ FACE recommends that personal protective equipment be worn when manual gauging is conducted. This is especially important under high 
temperatures.

Recommendation \#3: A safety and health plan based on a job hazard analysis should be developed by the employer and followed where workers are assigned tasks.

Discussion: Employers should conduct a job hazard analysis, with the participation of employees, of all work areas and job tasks. A job hazard analysis should begin by reviewing the work activities for which the employee is responsible, and the equipment that is needed. Each task is further examined for mechanical, electrical, chemical, or any other hazard the worker may encounter. A source of information on conducting a job hazard analysis can be obtained from the US Department of Labor. ${ }^{2}$ 


\section{APPENDIX}

\section{RECOMMENDED RESOURCES}

It is essential that employers obtain accurate information on health, safety, and applicable OSHA standards. NJ FACE recommends the following sources of information which can help both employers and employees:

\section{U.S. Department of Labor, Occupational Safety \& Health Administration (OSHA)}

Federal OSHA can provide information on safety and health standards on request. OSHA has several offices in New Jersey that cover the following counties:

急 Hunterdon, Middlesex, Somerset, Union, and Warren counties $.732-750-3270$

Essex, Hudson, Morris, and Sussex counties 973-263-1003

Bergen and Passaic counties. 201-288-1700

捅 Atlantic, Burlington, Cape May, Camden, Cumberland, Gloucester,

Mercer, Monmouth, Ocean, and Salem counties. $856-596-5200$

Web site: $\underline{w w w . o s h a . g o v}$

\section{New Jersey Public Employees Occupational Safety and Health (PEOSH) Program}

The PEOSH Act covers all NJ state, county, and municipal employees. Two state departments administer the Act: the NJ Department of Labor and Workforce Development (NJDLWD), which investigates safety hazards, and the NJ Department of Health (NJDOH), which investigates health hazards. PEOSH has information that may also benefit private employers.

NJDLWD, Office of Public Employees Safety

留Telephone: 609-633-3896

品 Web site: www.nj.gov/labor/lsse/lspeosh.html

$\underline{\text { NJDOH, Public Employees Occupational Safety \& Health Program }}$

㥜Telephone: 609-984-1863

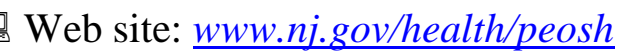

On-site Consultation for Public Employers

诲Telephone: 609-984-1863 (health) or 609-633-2587 (safety)

Web site: www.state.nj.us/health/eoh/peoshweb/peoshcon.htm 
New Jersey Department of Labor and Workforce Development, Occupational Safety and Health On-Site Consultation Program

This program provides free advice to private businesses on improving safety and health in the workplace and complying with OSHA standards.

留Telephone: 609-984-0785

Web site: $\underline{\text { ww.nj.gov/labor/lsse/lsonsite.html }}$

\section{New Jersey State Safety Council}

The New Jersey State Safety Council provides a variety of courses on work-related safety. There is a charge for the seminars.

留Telephone: 908-272-7712.

Web site: $\underline{w}$ ww.njsafety.org

\section{Internet Resources}

Other useful Internet sites for occupational safety and health information:

- $\mathrm{CDC} / \mathrm{NIOSH}-\underline{w w w . c d c . g o v / n i o s h}$

- USDOL Employment Laws Assistance for Workers and Small Businesses - www.dol.gov/elaws

- National Safety Council - $\underline{w w w . n s c . o r g}$

- NJDOH FACE reports - $\underline{w w w . n j . g o v / h e a l t h / s u r v / f a c e / i n d e x . s h t m l}$

- $\mathrm{CDC} / \mathrm{NIOSH}$ FACE - www.cdc.gov/niosh/face/faceweb.html

- OSHA - www.osha.gov

- ANSI-www.ansi.org

\section{REFERENCES}

1. Occupational Health and Safety Administration. CFR 1910.146. Permit Required Confined Spaces.

2. Job Hazard Analysis. US Department of Labor Publication \# OSHA-3071, 1998 (revised). USDOL, OSHA Publications, PO Box 37535, Washington DC 20013-7535 


\section{Fatality Assessment and Control Evaluation (FACE) Project}

\section{Investigation \# 13-NJ-049}

This report was prepared by staff members of the New Jersey Department of Health's Occupational Health Surveillance Unit. The goal of FACE is to prevent fatal work-related injuries by studying the work environment, the worker, the task, the tools the worker was using, the energy exchange resulting in the fatal injury, and the role of management in controlling how these factors interact. FACE gathers information from multiple sources that may include interviews of employers, workers, and other investigators; examination of the fatality site and related equipment; and reviewing OSHA, police, and medical examiner reports, employer safety procedures, and training plans. The FACE program does not determine fault or place blame on employers or individual workers. Findings are summarized in narrative investigation reports that include recommendations for preventing similar events. All names and other identifiers are removed from FACE reports and other data to protect the confidentiality of those who participate in the program.

NIOSH-funded state-based FACE Programs include: California, Iowa, Kentucky, Massachusetts, Michigan, New Jersey, New York, Oregon, and Washington. Please visit the NJ FACE Web site at www.nj.gov/health/surv/face/index.shtml or the CDC/NIOSH FACE Web site at www.cdc.gov/niosh/face/faceweb.html for more information.

The NJ FACE Project is supported by the Centers for Disease Control and Prevention (CDC). The contents of this report are solely the responsibility of the authors and do not necessarily represent the official views of the CDC.

Public Health Services Branch

Division of Epidemiology, Environmental and Occupational Health

Occupational Health Surveillance Unit

(609) 826-4984

nj.gov/health/surv/face/index.shtml 